\title{
Refúgio no Rio: \\ O Papel da Cidade na Integração Laboral dos Refugiados
}

\author{
Cleyton Costa Lima ${ }^{1}$
}

\section{Resumo}

O presente artigo tem como objetivo compreender quais condições precisam ser oferecidas pelas cidades para que solicitantes de refúgio e refugiados possam se manter na cidade e contribuir para o desenvolvimento econômico do município que o acolheu. Para isso, o estudo analisa o caso da cidade do Rio de Janeiro, dado que esta é a segunda maior cidade brasileira em recebimento e permanência de solicitantes e refugiados, parte por seu acesso logístico ser mais favorável para estrangeiros, parte devido às suas condições socioeconômicas. Nesse sentido, observa-se uma atuação quase inexistente da Prefeitura da Cidade do Rio de Janeiro no tratamento dessa questão, embora possua iniciativas para modificar tais práticas. Por conta disso, as organizações da sociedade civil, como a PARES Caritas, passam a ter um papel protagonista no processo de integração desses refugiados, mesmo que possuindo limitações. A partir dessas limitações, o artigo propõe formas de ação e resposta política por parte da Prefeitura da Cidade do Rio de Janeiro, assim garantindo uma integração laboral dos refugiados de forma positiva e eficaz, o que geram ganhos para os próprios deslocados, para as suas redes locais, e para a cidade como um todo, movimentando sua economia.

Palavras chave: Intergração Laboral - Refugiados - Rio de Janeiro - Sociedade Civil.

\footnotetext{
${ }^{1}$ Graduando em Relações Internacionais pela Pontifícia Universidade Católica do Rio de Janeiro (PUC-Rio), membro do Núcleo de Pesquisa em Refúgio (NPR/PET IRI PUC-Rio) e Child and Youth Advisor Committee Member na International and Canadian Child Rights Partnership. Este artigo é produto do Núcleo de Pesquisa em Refúgio do Programa de Educação Tutorial (NPR/PET) do Instituto de Relações Internacionais da Pontifícia Universidade Católica do Rio de Janeiro.Email: lima.costa.clyeton@gmail.com.
} 


\section{Abstract}

This article aims to understand what conditions must be given by the cities to asylum seekers and refugees to stay in town and contribute for the economic development of the municipality. To accomplish this objective, the study analyses the city of Rio de Janeiro's case, considering that this is the second Brazilian city that most receivees asylum seekers and refugees due to its socioeconomic conditions. In that sense, it is possible to observe an almost inexistent action from the Rio de Janeiro City Hall on this matter, even with some ongoing projects to change this situation. In this sense, the civil society organizations, such as PARES Caritas, has a protagonist role in the integration process of these refugees, but with limitations. Considering these limitations, the paper proposes possible actions and political answers for the Rio de Janeiro City Hall to guarantee a refugee's functional and positive labor integration, generating gains to the displaced persons, for its own local networks, and for the whole city, making the local economy stronger.

Keywords: Labor Integration - Refugees - Rio de Janeiro - Civil - Bureaucratic.

\section{Introdução}

O presente artigo visa compreender quais condições precisam ser oferecidas por cidades para que solicitantes de refúgio e refugiados possam auxiliar no desenvolvimento econômico delas. O estudo se justifica a partir de um momento de recessão no Rio de Janeiro entre 2014 e 2017, que gerou reduções em diversas áreas, inclusive na atuação dos governos em relação à integração laboral dos refugiados. Com isso, os agentes mais ativos nesse processo passam a ser as organizações da Sociedade Civil. No caso do Rio, a organização da Sociedade Civil mais ativa na cidade em relação à integração econômica é a PARES Caritas, criada na década de 1980 visando oferecer auxílio aos perseguidos políticos na América Latina. Entretanto, existem diversas questões sobre as quais essas organizações são incapazes de atuar, dado que estas não possuem, em grande parte dos casos, recursos financeiros e capacidades políticas para serem mais ativas. Dessa forma, é importante reconhecer quais são os fatores que influenciam e dificultam o acesso dos refugiados à integração laboral, como a falta de documentação, a revalidação de diplomas e os casos de xenofobia sofridos por refugiados no Rio de Janeiro. Assim, cabe compreender quais as normas e regras que competem ao município, 
nesse caso, o Rio de Janeiro, que permite atuar nesse campo de diversas formas, e verificar se essas normas estão sendo cumpridas durante o processo de integração laboral da população refugiada, com seus sucessos e falhas.

$\mathrm{Na}$ primeira seção, realizarei uma revisão da literatura teórica sobre a relação entre o refugiado/solicitante de refúgio e o desenvolvimento econômico, principalmente tomando como base os pensamentos de Tom Kuhlman (1991), Hein de Haas (2012) e Chambers (1986), que analisam os impactos da população refugiada no desenvolvimento econômico de diversas regiões e apontam mudanças positivas, como 0 incentivo à produção $e$ ao desenvolvimento. Os três autores defendem que para que tal desenvolvimento seja realizado, é fundamental que exista uma estrutura básica que permita que o crescimento seja alcançado, caso contrário, há uma dificuldade maior na integração no mercado de trabalho e, por consequência, na sociedade local.

$\mathrm{Na}$ segunda seção, apresentarei dados estatísticos sobre quem são esses refugiados que se deslocam para a cidade do Rio de Janeiro. Nesse sentido, será possível compreender seus locais de origem, motivações e quais são as principais necessidades desses indivíduos que optam pelo Rio de Janeiro como seu novo lar. Para isso, utilizarei relatórios do Instituto de Pesquisa Econômica Aplicada (IPEA), do Comitê Nacional para os Refugiados (CONARE) e do Alto Comissariado das Nações Unidas para Refugiados (ACNUR), que coletam dados entre 2014 e 2017.

$\mathrm{Na}$ terceira seção, mapearei, a partir das normas e regras que a cidade do Rio de Janeiro ratifica e que definem o âmbito de atuação da Prefeitura, quais são os órgãos que são responsáveis por formular e aplicar políticas públicas de integração laboral para a população refugiada, e quais os resultados positivos e negativos para tais políticas. Dessa forma, buscarei compreender qual a competência do município nesse processo de integração laboral, quais são as secretarias e agências municipais que atuam nesse campo e quais são os papéis da Prefeitura por lei. Nesse sentido, a partir da análise da Prefeitura da Cidade do Rio de Janeiro, há pouca disponibilidade de informações sobre a população refugiada, especialmente em relação à integração laboral, mesmo com o desenvolvimento de um Plano Intersetorial de Atendimento ao Refugiado e Migrante (PREFEITURA DA CIDADE DO RIO DE JANEIRO, 2014)², que também dispõe de poucos dados públicos.

\footnotetext{
2 Plano que estava em desenvolvimento no ano de 2014, entre a Prefeitura do Rio de Janeiro e suas secretarias, com destaque para a Secretaria Municipal de Assistência Social e Direitos Humanos. Não há mais informações sobre o andamento deste plano desde então.
} 
$\mathrm{Na}$ quarta seção, compreenderei fatores que dificultam o acesso à integração laboral dos refugiados, como a ausência de documentos, a falta de reconhecimento da formação anterior e a xenofobia, a partir do uso de entrevistas realizadas pelo Alto Comissariado das Nações Unidas para Refugiados. Defendo que tais práticas dificultam o processo de integração laboral dos refugiados a partir do momento que são considerados "de menor valor" e relegados a empregos não formais e que não fornecem direitos trabalhistas. Essa lógica promove formas diversas de discriminação, desrespeito aos direitos trabalhistas dos refugiados, casos de trabalho escravo, assim como uma maior dificuldade no acesso a documentações e empregos formais. A insuficiência das práticas da Prefeitura do Rio de Janeiro intensifica esses problemas a partir do momento que as medidas para responder essas questões ou inexistem, ou são insuficientes e pouco coordenadas com outros atores presentes.

Na quinta seção, farei uma breve análise do comportamento e atuação de organizações da Sociedade Civil na cidade do Rio de Janeiro, a partir do caso da PARES Caritas como modelo, visto que esta é a organização mais atuante no processo de integração laboral dos refugiados, em comparação a outras organizações da Sociedade Civil presentes na região, como a Fundação Casa de Rui Barbosa, que possui uma ação voltada para à pesquisa e ao advocacy. Ao mesmo tempo, criticarei o fato dessas organizações, devido à baixa atuação da Prefeitura nessa questão, acabarem sendo responsabilizadas totalmente pelo processo de recepção e integração da população refugiada, quando tais questões também devem ser promovidas pelos governos municipais. Por conta dessa insuficiência, principalmente por falta de recursos e competências legais, a população refugiada se torna carente de diversos direitos concedidos a eles por lei.

Cabe também levantar um possível questionamento relacionado à capacidade de agência do refugiado dentro desse ambiente. Nesse sentido, outros autores argumentam que os refugiados sofrem profundamente em seu processo de integração, dado a necessidade da ação dos governos (municipal, estadual e federal) e as diferenças culturais entre tais indivíduos e o local. Entretanto, o refugiado é perfeitamente capaz de se integrar a partir da formação de redes locais de suporte e auxílio entre refugiados de mesma nacionalidade ou de cultura semelhante, contudo, existem diversos campos que ele não pode ter agência autônoma. Nesses ambientes, a burocracia estatal é fundamental para a 
oferta de documentos fundamentais para a permanência dos refugiados no Rio de Janeiro, assim como a garantia do cumprimento dos direitos trabalhistas concedidos a eles, e a punição aos empregadores em caso de violação de direitos.

\section{O Refugiado e o Desenvolvimento Econômico: uma revisão teórica}

Tom Kuhlman (1991) busca organizar um modelo teórico para o processo de integração da população refugiada em países em desenvolvimento, visto que existem poucos estudos envolvidos nessa questão. Nesse sentido, ele conceitua integração como um cenário onde "os migrantes mantêm sua própria identidade, mas fazem parte da sociedade receptora ao ponto que a população e os refugiados possam viver em conjunto de forma aceitável" (Kuhlman, 1991, p. 6). Entretanto, ele reconhece que tal conceito é vago, a partir do momento que a ideia de "aceitável" determina um conjunto de valores que devem ser seguidos, ignorando as subjetividades e variâncias entre as culturas e promovendo um julgamento de valor subjetivo.

Com isso, Kuhlman desenvolve um conceito para especificar melhor a ideia de integração. Cabe destacar que tal conceituação é unificada em sua fala, contudo tais elementos serão separados neste artigo devido à sua importância na compreensão do processo de integração. Em primeiro lugar, os refugiados estarão integrados quando puderem "participar na economia do receptor com suas capacidades e valores culturais" (Kuhlman, 1991, p. 8), ou seja, quando eles puderem promover suas ações tendo a liberdade de agir conforme suas habilidades e sua cultura.

Além disso, outro elemento de análise para a definição de "integração" é quando o refugiado segue um padrão de vida que satisfaça exigências mínimas (moradia, serviços públicos, saúde e educação). A partir disso, tais indivíduos poderiam ser capazes de se desenvolver economicamente e em relação ao trabalho, promovendo mudanças e melhorias na economia local.

Kuhlman também desenvolve outros pontos referentes a características intrínsecas do conceito de "integração": se o refugiado consegue ajustar-se psicologicamente à sua nova situação, se os padrões de vida e oportunidades econômicas não são deteriorados pelo influxo de refugiados (ou seja, se a chegada de um grande número de indivíduos gera danos econômicos à 
população), se a fricção entre os refugiados e a população local não é pior se comparada à existente entre os locais, e se o refugiado não sofrer mais discriminação do que os outros grupos anteriores a ele (Kuhlman, 1991). Apenas com todos esses elementos o indivíduo estará integrado por completo em uma sociedade, de acordo com Kuhlman.

Em relação à ideia de integração econômica, Kuhlman delimita os critérios para tal fenômeno: participação adequada na economia, um salário que permita um padrão adequado de vida, acesso igualitário a bens e serviços cujo acesso não é determinado apenas por renda, e a não deterioração dos fatores socioeconômicos em relação aos critérios anteriores (Kuhlman, 1991). Esse último critério, referente à deterioração dos fatores socioeconômicos a partir da chegada de populações refugiadas é difícil de ser medido. Isso justifica-se pela grande dificuldade em analisar todos os elementos socioeconômicos presentes em uma sociedade, assim como a necessidade de realizar um estudo geral da mudança do local que recebe refugiados ${ }^{3}$ (Kuhlman, 1991).

$\mathrm{O}$ autor reconhece algumas questões que surgem a partir deste conceito, contudo, ele as deixa em aberto. Por exemplo, o conceito de integração econômica apresentado por Kuhlman não põe em pauta as diferenças nos padrões de vida dentro do país de origem, principalmente nos âmbitos de gênero, visto suas diferenças nos processos de integração, que podem ter maior ou menor demanda de determinadas questões. Um outro exemplo são os casos de mulheres com crianças de colo, que demandam políticas distintas (garantia de creche e escola, sistema de saúde público) de um homem sozinho, que demandará um outro conjunto de normas (um sistema de saúde voltada para as doenças comuns no sexo masculino).

Por fim, outra questão fundamental levantada por Kuhlman é a defesa da necessidade de tornar mais clara a ideia de padrão de vida aceitável, visto que esse é subjetivo de acordo com a cultura de cada local, ainda mais em ambientes multiculturais. Uma solução proposta pelo autor é o uso do conceito de um padrão de vida mínimo determinado. Dessa forma, através desses padrões culturais, é possível compreender o grau de privação na capacidade de consumo, um dos impedimentos ao desenvolvimento socioeconômico do refugiado.

\footnotetext{
${ }^{3}$ Um exemplo disso é a dificuldade em comparar os impactos socioeconômicos da população migrante venezuelana na cidade de Pacaraima, em Roraima, a partir da análise do período anterior e posterior à chegada destes ao Brasil.
} 
De Haas (2012), por outro lado, promove uma conversação com Tom Kuhlman (1991) a partir do momento que defende que a migração é o resultado da falha do desenvolvimento do país de origem, podendo assumir um caráter negativo ou positivo na relação entre migração e desenvolvimento. Para ele, o caráter negativo seria apresentado como um outro elemento de manutenção do status quo: aqueles refugiados que já possuem riquezas e boas condições de vida se manteriam assim, e as pessoas carentes migrantes não teriam possibilidade para a garantia de seu sustento e de seu desenvolvimento socioeconômico. Entretanto, quando há uma estrutura eficaz para a garantia dos direitos dos refugiados, consideramos uma integração positiva. Nessa situação, os refugiados teriam condições suficientes de ter emprego (ou empreender), o que geraria um aumento na renda deles, podendo acarretar o envio dos ganhos excedentes aos seus países de origem. Um exemplo dessa dualidade é o caso da Alemanha, que até a década de 2000, possuía diversas políticas de contenção e impedimento de migrantes e refugiados a postos de trabalho. A partir de 2016, o governo alemão compreende que o acesso ao emprego é fundamental para uma boa integração dos refugiados, e passa a reduzir o tempo de espera para acessar empregos e a garantia do direito de residência a refugiados que trabalhassem na Alemanha durante determinado período de tempo (Laubenthal, 2019).

A migração, no ponto de vista de De Haas (2012) pode reforçar desigualdades a partir da distinção entre a migração daqueles que possuem boas condições financeiras e aqueles que não possuem. Ao mesmo tempo, a migração pode prover o acesso à educação, saúde e ofertas de emprego para as populações de baixa renda, garantindo um aumento na qualidade de vida desses indivíduos.

Para isso, ele afirma que é necessário compreender que as migrações sempre vão sustentar e reforçar desigualdades econômicas entre os mais pobres e os mais ricos, embora os últimos tenham maior capacidade de coordenação entre si em busca de mudanças e melhorias na qualidade de vida do país de origem. Assim, De Haas (2012) sustenta que a migração parece reforçar tendências de mudanças sociais, econômicas e políticas que já existem - sejam elas positivas ou negativas.

De Haas, a partir dessa afirmação, defende que em países cuja estrutura é desfavorável ao desenvolvimento socioeconômico dos migrantes, ou seja, com ausência de mudanças políticas domésticas, dificilmente os refugiados serão 
capazes de melhorarem suas condições de vida e oferecerem ganhos sociais e econômicos a outros locais. Em contrapartida, se o Estado desenvolve políticas que permitem o investimento, circulação e apoio aos refugiados, eles terão maior capacidade de melhorarem suas condições de vida. Por consequência desse desenvolvimento, há a promoção de melhorias ao local onde ele vive (De Haas, 2012), o que se relaciona com os elementos levantados por Kuhlman como fatores-chave para que o refugiado seja capaz de se integrar economicamente.

Robert Chambers (1986) analisa em seu artigo o impacto dos refugiados em países em desenvolvimento, argumentando sobre o desenvolvimento econômico. Para ele, ao mesmo tempo que tal relação entre refugiados e os países em desenvolvimento pode ser positiva, a partir do favorecimento das relações comerciais com o artesanato e a agricultura, essa relação pode também ser negativa, com o aumento da criminalidade nas fronteiras e os conflitos por terra entre refugiados e a população local. Para definir a qualidade dessa relação, Chambers afirma que a capacidade do refugiado em contribuir para o desenvolvimento econômico ou não de certa localidade depende principalmente das intervenções e políticas oficiais: quando nada ou pouco é feito, o refugiado tem baixa capacidade de contribuir com o desenvolvimento econômico do município. Por consequência, há uma menor empregabilidade desse refugiado, um incremento no trabalho autônomo e na ilegalidade.

Por outro lado, em municípios que possuem uma forte ação política voltada aos refugiados, observamos uma maior capacidade do refugiado em melhorar sua qualidade de vida e trazer ganhos econômicos e sociais a sua região. Os anfitriões teriam muito mais ganhos financeiros, comerciais e sociais se os refugiados possuíssem capacidades e direitos para se desenvolverem, e por consequência, melhorarem a qualidade do ambiente onde vivem. Um exemplo são as políticas promovidas pela Alemanha, que foram capazes de triplicar o número de refugiados empregados (REUTERS, 2018) e com capacidades de melhoria de vida e crescimento econômico.

Como conclusão sobre o posicionamento desses autores, podemos observar algumas divergências entre eles. Dentre outras questões, cabe destacar que a forma do estudo de Kuhlman busca trazer fundamentos teóricos para a análise da integração dos refugiados à sociedade, enquanto De Haas e Chambers buscam observar qual o papel dos governos nesse processo. Entretanto, os três autores também defendem questões semelhantes. Para os três, é fundamental que os refugiados tenham uma participação adequada na 
economia, um salário digno, a liberdade no acesso a bens e serviços e que a economia local não sofra negativamente com a inclusão da população refugiada. Além disso, mesmo que seus argumentos se guiem de formas opostas, eles defendem que o Estado tem papel significativo, e em certos casos fundamental, para que tais refugiados sejam incluídos na sociedade, permitindo seu desenvolvimento econômico e laboral. Dessa forma, justifica-se a necessidade de compreender quais são as práticas que a cidade do Rio de Janeiro se compromete a cumprir sobre a questão da integração laboral das populações refugiadas.

\section{Refugiados no Rio de Janeiro: quem são?}

Segundo o relatório "Refúgio em Números", do Comitê Nacional para os Refugiados (CONARE), o Brasil recebeu entre 2014 e 2017 mais de 100 mil solicitações para o reconhecimento da situação de refugiado, sendo em sua grande maioria oriundos da Venezuela e do Haiti. Dentre esses, cerca de 35.500 pessoas tiveram sua solicitação atendida, em sua maioria da Síria (Conare, 2018). Existem poucos dados organizados para analisar a quantidade de imigrantes e refugiados presentes no Rio de Janeiro entre 2014 a 2017, mas é possível reconhecer a grande presença desses imigrantes e refugiados a partir dos processos de deslocamento para o país devido as crises no Haiti e na República Democrática do Congo.

Em 2017, um relatório produzido pelo Instituto de Pesquisa Econômica Aplicada (IPEA) se propôs a analisar o perfil dos migrantes e refugiados que se deslocaram para o Brasil, compreendendo questões como origem, gênero e razão para o deslocamento. O relatório do IPEA apresenta dois elementos importantes que justificam a relevância de pensar a cidade do Rio de Janeiro para a resposta das cidades à questão da integração laboral dos refugiados: ela ser a segunda principal cidade de chegada e de domicílio de migrantes, ficando atrás apenas da cidade de São Paulo (Lima et al, 2017). Uma das principais razões para isso é o fato do Rio, junto a Guarulhos, comportarem os dois maiores aeroportos internacionais do Brasil, embora o Rio de Janeiro possua uma maior taxa de permanência destes que chegam pelos aeroportos, em comparação à cidade de Guarulhos, dado que os migrantes se deslocam para a cidade de São Paulo visando melhores condições de vida (INDA, 2017). O relatório também apresenta elementos relacionados à nacionalidade desses 
migrantes, e sua distribuição pelo país. Esses dados podem ser observados no gráfico abaixo.

Gráfico 1: Refúgio no Brasil, compreendendo a área de chegada e a nacionalidade dos migrantes

\section{Refúgio no Brasil (Área de Chegada x Nacionalidade)}

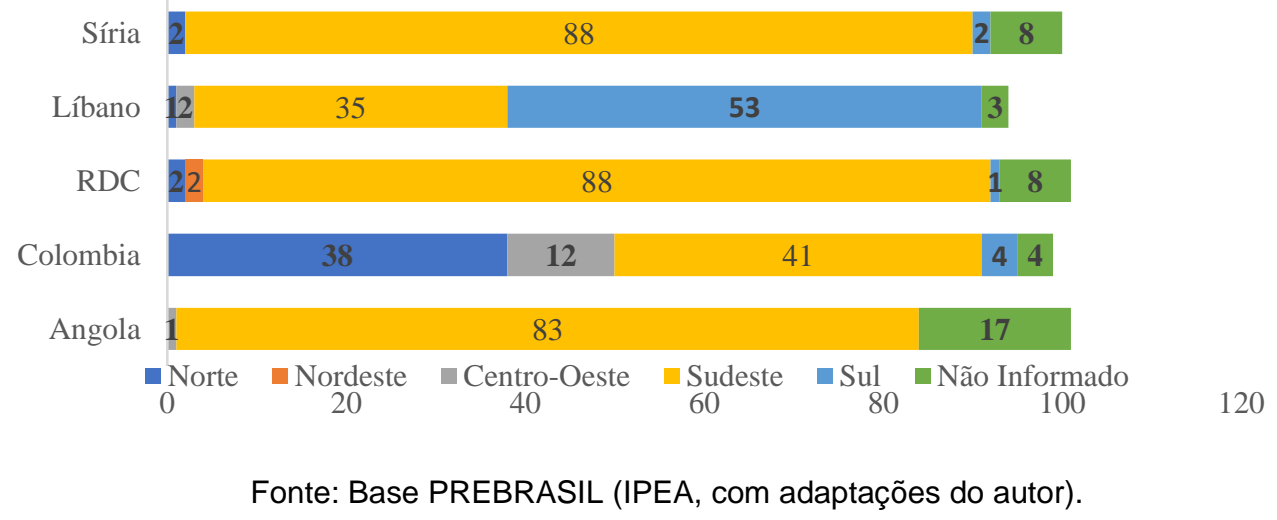

Nesse gráfico, podemos observar alguns elementos relevantes para compreender os países de origem dos refugiados no Rio de Janeiro. Nessa análise do IPEA, observa-se uma frequência grande de angolanos, congoleses e sírios na região Sudeste, ultrapassando $80 \%$ dos casos (Lima et al, 2017). Cabe reconhecer também que um fluxo grande de refugiados de origem venezuelana chega ao Brasil a partir de 2015 e muitos passam a residir no Rio de Janeiro. Contudo, a dificuldade em contabilizar quantas pessoas saíram da Venezuela e se deslocaram para o Brasil (Coury et al., 2018), em especial ao Rio de Janeiro, impede a comparação com outras nacionalidades.

Uma outra fonte de dados para compreender quantos e quem são os refugiados que migram para o Rio de Janeiro são os dados da PARES Caritas, organização da sociedade civil que possui importante atuação no processo de recebimento, acolhimento e integração dos refugiados no município. Segundo a organização, o Rio de Janeiro possuía 4341 refugiados e 2948 solicitantes no ano de 2017. Desses, cerca de $70 \%$ são do sexo masculino e vêm principalmente da Angola, Venezuela, República Democrática do Congo (RDC), Cuba e Síria (CARITAS, 2017). Contudo, cabe reconhecer que esses dados não necessariamente são totalmente compatíveis com a realidade, dado que nem todos os refugiados são atendidos. Existe um movimento para maior participação 
e atuação da sociedade civil para os refugiados, considerando ainda mais a baixa ou falta de atuação das instâncias governamentais, que analisaremos mais à frente.

Em um relatório de 2019, produzido pelo Alto Comissariado das Nações Unidas para Refugiados (ACNUR) em parceria com diversas universidades brasileiras e a Fundação Casa de Rui Barbosa, observamos alguns dados sobre quem são esses refugiados e quais são suas características gerais. De acordo com o relatório, o Rio de Janeiro continua sendo o segundo município com mais refugiados no país, mesmo com o crescimento do número no estado de Roraima, tendo quase $20 \%$ dos casos analisados pelo documento. A grande maioria desses refugiados são indivíduos economicamente ativos, ou seja, têm entre 18 e 49 anos, são de origem síria ou congolesa, do sexo masculino e parte casado, parte solteiro. A considerável maioria da população é negra e as pessoas brancas são de origem síria (ACNUR, 2019).

A maioria dos indivíduos tem pelo menos o Ensino Médio completo, alguns são pós-graduados. Isso aponta um dos grandes impeditivos para uma plena integração laboral: a dificuldade em revalidar os diplomas. Outra questão importante é que muitos dos entrevistados afirma falar português em nível básico, mas a demanda por cursos de língua portuguesa, que ofereceriam condição suficiente para permanência e melhoria na qualidade de vida, é grande e a oferta é insuficiente (ACNUR, 2019).

Quanto à questão dos empregos, os entrevistados apontam que quase $60 \%$ possuem emprego, cerca de $20 \%$ estão procurando e $5,7 \%$ estão desocupados. A pesquisa também afirma que $22 \%$ desenvolvem suas próprias empresas, empregando às vezes outros trabalhadores. Além disso, cabe reconhecer que o estudo aponta que grande parte dos refugiados tem interesse em empreender e criar suas próprias fontes de renda, mas o principal problema é a falta de recursos financeiros (ACNUR, 2019). Isso apresenta um movimento grande de práticas de empreendedorismo, a partir de um cenário positivo para a inclusão dessas empresas no mercado de trabalho ou pela falta de uma integração laboral suficientemente eficaz para todos os refugiados. Tal questão precisa ser mais bem estudada a fim de compreender quais são os fatores para tal processo de empreendedorismo refugiado, e quais os impactos disso para o refugiado e a sociedade. 


\section{Rio de Janeiro: leis e práticas}

Segundo o Estatuto do Refugiado de 1951, os governos devem garantir ao refugiado residente "o tratamento mais favorável dado, nas mesmas circunstâncias, aos nacionais de um país estrangeiro no que concerne ao exercício de uma atividade profissional assalariada" (ACNUR, 1951, p.9). Isso determina que o refugiado não deve ser tratado de forma distinta dos nacionais devido à sua condição jurídica, mas deve ser reconhecido no âmbito trabalhista da mesma forma que qualquer outro residente do país. Cabe reconhecer que tal princípio também será aplicado para o caso de profissões liberais, como na agricultura, na indústria, no artesanato e no comércio, desde que devidamente certificados. Tal norma permite que os refugiados, independente de sua profissão, tenham os mesmos direitos e deveres de qualquer cidadão local.

O artigo 24 do mesmo Estatuto (ACNUR, 1951) determina que os refugiados residentes devem ter a garantia de determinados direitos em relação ao trabalho: a remuneração, as horas de trabalho (e extras), a formação profissional, férias remuneradas, a permissão que mulheres trabalhem (dado que, em muitos países, as mulheres não possuem tal direito), e todas as outras convenções inseridas dentro do país em questão (ACNUR, 1951). Tais direitos determinados pelo documento são mais uma expressão de garantia da semelhança de tratamento laboral entre refugiado e local, ao mesmo tempo que determina a garantia de direitos trabalhistas que permitem a sobrevivência desse refugiado, assim como o seu desenvolvimento econômico e social, a partir do aumento de renda e da qualidade de vida.

Cabe ainda destacar que o Estatuto é voltado para os Estados nacionais, não abarcando o papel dos governos municipais dentro de suas regras, em parte pelo baixo reconhecimento do papel dessas na integração dos refugiados, e o reconhecimento constitucional do papel dos municípios como atores no plano internacional apenas a partir da Constituição Brasileira de 1988, no artigo 52 inciso V (BRASIL, 1998).

Além disso, a Declaração de Cartagena de 1984 determina que os Estados devem:

Estudar com os países da região que contam com uma presença maciça de refugiados, as possibilidades de integração dos refugiados na vida produtiva do país, destinando os recursos da comunidade internacional que o ACNUR canaliza para a criação ou geração de empregos, possibilitando assim o desfrutar dos direitos econômicos, sociais e culturais pelos refugiados (ACNUR, 1984). 
O documento reforça o papel dos governos receptores de refugiados na América Latina defendendo que devem ter um papel ativo na geração de empregos, a fim de que o refugiado possa viver da mesma forma que qualquer indivíduo, buscando sua sobrevivência e seu desenvolvimento no país que o acolheu. Tal inserção na Declaração, voltada principalmente à garantia do reconhecimento do status de refugiado e de seus direitos dentro do país receptor, explicita a relevância da integração laboral na busca pela melhoria da qualidade de vida do refugiado, e o seu próprio desenvolvimento econômico e social.

A Constituição de 1988 não possui legislações específicas voltadas à competência da integração laboral da população refugiada, entretanto, de acordo com o quinto artigo da constituição inciso XIII, "é direito de todo indivíduo possuir liberdade de exercer qualquer trabalho, desde que sejam atendidas as qualificações profissionais estabelecidas por lei” (BRASIL, 1988). Tal direito é expandido no artigo 7, que determina quais são os direitos do trabalhador no Brasil, como a garantia de salários em equivalência à função, a igualdade de direitos entre o assalariado e o profissional liberal, e a discriminação de funcionários (BRASIL, 1988). Tais artigos são base para pensar os direitos de trabalho para os refugiados dentro do Brasil, e todas as ações voltadas ao Emprego no âmbito nacional, estadual e municipal devem seguir tais princípios, incluindo as políticas de integração laboral dos refugiados.

O Governo do Estado do Rio de Janeiro em 2015 promoveu a lei 826/2015 que instituiu o Programa Estadual de Acolhimento de Refugiados no Estado do Rio de Janeiro, buscando "facilitar a adaptação dos mesmos no território fluminense" (ALERJ, 2015). Esse programa desenvolve todo o âmbito de atuação do Estado do Rio de Janeiro em relação ao refúgio, desde o acolhimento dos refugiados até sua inclusão às redes públicas de saúde, assistência social, educação e emprego. No segundo artigo, é posto como objetivo o encaminhamento desses indivíduos para o Centro Público de Emprego, Trabalho e Renda (ALERJ, 2015), órgão voltado para a divulgação de vagas de emprego e processos seletivos no estado do Rio de Janeiro. O reconhecimento de tal objetivo é uma forma do estado oferecer maior quantidade de informação para tais indivíduos, que sofrem com o acesso às vagas devido ao desconhecimento do idioma e das fontes de compartilhamento.

Além desse objetivo, levantado pelo segundo artigo, o sexto artigo desse programa determina que: 
Art. 6o - Serão empreendidas ações voltadas para o aproveitamento do potencial cultural dos refugiados, tais como:

I - Conhecimentos gastronômicos;

II - Dança;

III - Música;

IV - Artesanato;

V - Outras manifestações regionais

$\S 1^{\circ}$ - As ações de que trata o caput deste artigo consistirão no aproveitamento da mão de obra dos refugiados para comercialização do produto em feiras e eventos organizadas pelo órgão competente do Poder Executivo.

$\S 2^{\circ}$ - Os valores arrecadados com a exposição e comercialização dos produtos e/ou com as apresentações culturais tradicionais, serão revertidos aos refugiados, a fim de integrarem a sua renda, sendo vedada qualquer tipo de desconto.

§3ํ- - O Poder Executivo poderá firmar convênios com instituições privadas para contratação de mão de obra dos refugiados para aproveitamento do potencial cultural de que trata a presente Lei. (ALERJ, 2015).

Assim como o encaminhamento do refugiado para os centros de emprego, tais ações empreendidas são uma forma de promover uma alternativa de renda para os refugiados a partir da promoção dos componentes culturais de seus países de origem, como a dança, a música, a gastronomia e o artesanato, dentro do estado do Rio de Janeiro. Isso permite que refugiados sem uma formação técnica profissional e sem condições financeiras possam ter uma fonte de emprego e renda a partir da sua vivência e experiência cultural, além de contribuir para a manutenção da cultura desses refugiados e a construção de uma identidade multicultural dentro do estado.

No plano legislativo municipal, ao realizar a busca na plataforma de leis oferecidas pela Câmara dos Vereadores do Rio de Janeiro, órgão competente pela produção de leis, observamos apenas uma lei (ainda em discussão no momento em que este artigo é redigido) que tem relação com a questão do refúgio: a determinação do Dia do Refugiado no dia 20 de junho. Isso aponta uma baixa produção de políticas públicas para essa parcela da população que compõe cerca de $20 \%$ dos refugiados no Brasil (CONARE, 2018), e acaba tornando a cidade do Rio de Janeiro menos ativa em todos os processos de inserção, incluindo a laboral, da população refugiada residente na cidade.

Além disso, ao analisar a estrutura das Secretarias Municipais da Cidade do Rio de Janeiro, através do Sistema Integrado de Codificação Institucional (SICl) e da página da web da Prefeitura da Cidade do Rio de Janeiro, observa-se a baixa ação de quaisquer instituições, órgãos ou secretarias voltadas 
diretamente para a questão dos refugiados, incluindo a integração laboral, tendo apenas ações pontuais como o apoio à Copa dos Refugiados ou debates ad hoc sobre a questão do refúgio. Tal ausência aponta para uma baixa atuação do Poder Executivo da cidade em relação a políticas voltadas para a população refugiada, incluindo aquelas voltadas para os refugiados, mesmo possuindo órgãos possíveis para a realização dessas como a Secretaria Municipal de Assistência Social e Direitos Humanos (SMASDH) e a Secretaria Municipal de Desenvolvimento, Emprego e Inovação (SMDEI).

Visando oferecer uma resposta à baixa atuação do município frente à questão dos Direitos Humanos, a SMASDH, em seu "1 Plano Municipal de Direitos Humanos - Por um Rio de Direitos" (2014) desenvolve diversas diretrizes para proteger e garantir os Direitos Humanos a todos os indivíduos da cidade do Rio de Janeiro. Nesse sentido, o primeiro Objetivo Estratégico da Diretriz 4 do plano, fomenta projetos que garantam direitos iguais a tais populações, reconhecendo as diversidades desses refugiados. A partir dessa diretriz, a Prefeitura da Cidade do Rio de Janeiro se compromete a desenvolver políticas de incentivo à inclusão social dos refugiados, não de forma homogeneizante, mas reconhecendo suas particularidades (Prefeitura da Cidade do Rio de Janeiro, 2014).

Além disso, a Diretriz 1, a partir do segundo objetivo estratégico, apresenta um primeiro movimento de integração laboral da população refugiada. O segundo objetivo estratégico planeja promover "inclusão social por meio de programas de reciclagem e da economia solidária", e tem como uma de suas ações a transformação de materiais recicláveis em recursos para a população, incluindo as vulneráveis, como os refugiados (Prefeitura da Cidade do Rio de Janeiro, 2014). Entretanto, tal prática desconsidera as grandes diversidades características dos refugiados, como a formação em seus países de origem e suas capacidades individuais, não inserindo-os à sociedade de forma ideal.

É importante também apontar um recente esforço da Prefeitura em desenvolver planos de ação e políticas públicas voltadas para a população refugiada. No Plano Municipal de Assistência Social 2018-2011, há a inclusão de um novo objetivo da SMASDH que se relaciona com a questão do refúgio.

Incentivar e difundir a cultura em Direitos Humanos na cidade do Rio de Janeiro assegurando a equidade no acesso aos direitos fundamentais, o respeito à diversidade e o combate a toda forma de preconceito reconhecendo e protegendo os indivíduos como iguais na diferença e, propiciando que o respeito aos Direitos Humanos seja concebido como ação integrada de governo e política de Estado, relativa a todos os seguimentos (criança e adolescentes, idoso, juventude, mulher e diversidade racial), bem como participar e contribuir para a 
elaboração do Plano Municipal Intersetorial de Atendimento aos Imigrantes e Refugiados, articulando as diretrizes já formuladas pelo MDS sobre a temática (Prefeitura da Cidade do Rio de Janeiro, 2018).

A inclusão deste objetivo como fundamento das práticas promovidas pela Secretaria aponta um novo movimento da Prefeitura em desenvolver ações voltadas para a população refugiada. Também deve ser destacado nesse objetivo a busca pela elaboração do Plano Municipal Intersetorial de Atendimento aos Imigrantes e Refugiados, que planeja determinar de forma mais clara as competências e as iniciativas a serem promovidas pela Prefeitura da Cidade do Rio de Janeiro no que concerne as populações refugiadas residentes no Rio de Janeiro. É fundamental que esse Plano reconheça as individualidades dessas populações e desenvolva práticas que permitam sua inserção, principalmente no âmbito laboral.

Cabe reconhecer que é necessário um estudo mais aprofundado acerca do andamento na formulação do Plano Intersetorial de Atendimento aos Imigrantes e Refugiados, assim como compreender de que formas tais Secretarias Municipais poderiam contribuir, de forma conjunta, na integração laboral desses refugiados na cidade do Rio de Janeiro em sincronia ao praticado pelo Estado do Rio de Janeiro e a Sociedade Civil. Ainda assim, a partir da falta de clareza e institucionalização dessas secretarias da Prefeitura em relação ao atendimento aos refugiados, é possível compreender a razão para a baixa participação do Executivo Municipal na integração laboral dos refugiados, o que torna o papel da Sociedade Civil ainda mais fundamental para garantir a sobrevivência e o desenvolvimento desses indivíduos na cidade.

\section{Obstáculos para uma Integração Laboral Eficiente}

Existem diversos elementos apontados pelos refugiados, quando entrevistados pelo ACNUR, que dificultam o acesso aos processos de integração laboral. Entre eles se destacam a baixa oferta de cursos de língua portuguesa, a falta de documentação oficial e casos de discriminação racial e xenofobia. $O$ relatório lançado em 2019 pelo ACNUR, reforça as questões levantadas pelos refugiados como fatores que dificultam o acesso a empregos e uma maior capacidade de desenvolvimento econômico: a falta de domínio do português, junto aos casos de xenofobia compõem pouco mais de $20 \%$ das críticas; a falta de documentos é citada por 54 dos 400 entrevistados (ACNUR, 2019). 
A dificuldade em relação à falta de conhecimento do português está relacionada com a origem desses refugiados. Como apontado anteriormente, a grande maioria dos refugiados que residem no Rio de Janeiro são de origem síria ou congolesa, países que não são lusófonos. Devido a isso, tais indivíduos antes de serem devidamente integrados ao mercado de trabalho, necessitam aprender português para se manter no país. A principal instituição que atua na solução desse problema é a PARES Caritas em parceria com a Universidade Estadual do Rio de Janeiro (UERJ), que concede o espaço e oferece material didático para as aulas (CARITAS, s/d). Entretanto, cabe reconhecer que a oferta dessas aulas é limitada, dado que sua duração é muitas vezes insuficiente para um aprendizado que permita que um estrangeiro consiga se inserir no mercado de trabalho e demandar seus direitos básicos. Além disso, cabe reconhecer que as aulas oferecidas no período da manhã são inacessíveis para os refugiados que já conseguiram um emprego, mas ainda necessitam de um domínio maior da língua para a melhor execução de suas tarefas (CARITAS, s/d).

Outra questão levantada pelos refugiados é a dificuldade no processo de obtenção de documentos tanto para reconhecer uma formação acadêmicoprofissional, quanto para o reconhecimento de seu status como refugiado no Brasil, que se tornam um impeditivo pela burocracia do processo, a demora no recebimento e a falta de acesso às oportunidades quando não se é reconhecido como refugiado. Segundo o estudo realizado pelo ACNUR, 166 dos 400 refugiados entrevistados possuem, no mínimo, ensino superior completo, mas apenas 14 conseguiram revalidar seus diplomas para que o grau seja reconhecido (ACNUR, 2019). Isso impede que esses indivíduos consigam exercer as mesmas profissões que exerciam em seus países de origem, e os obriga a praticar tarefas que não estão habituados, em grande maioria com menor remuneração que seus empregos originais.

Observa-se uma grande dificuldade no acesso a documentos como a Carteira Nacional de Trabalho e Previdência (CNTP) e o Registro Nacional de Estrangeiros (RNE), que são fundamentais para a prática de empregos legais e que seguem todos os direitos e deveres trabalhistas dentro da Constituição de 1988. Segundo a Caritas, o Rio de Janeiro em 2017 dispunha de 4341 refugiados reconhecidos e cerca de 3 mil aguardando o reconhecimento de sua solicitação (CARITAS, 2017). Considerando o processo burocrático de reconhecimento dos refugiados, que em parte considerável dos casos possui uma longa duração, tais indivíduos são incapazes de obter empregos que 
cumpram com os seus direitos, os obrigando a trabalharem em subempregos ou viverem na informalidade. Além disso, foram reportados casos de empregadores que se recusaram a reconhecer os direitos trabalhistas e contratuais dos refugiados mesmo eles apresentando a documentação completa.

A partir dessas diversas problemáticas que acercam o acesso ao emprego pelos refugiados, o trabalho informal e o empreendedorismo se tornam alternativas viáveis para sua permanência na cidade. Segundo um recente estudo realizado pelo ACNUR (2019), dentro de $57 \%$ de pessoas que estão empregadas, $22 \%$ trabalham em áreas empresariais, 17,9\% trabalham por conta própria e $4,1 \%$ empregam uma ou mais pessoas. Nesse sentido, a área mais comum de trabalho é a da gastronomia, em especial para as populações sírias e de origem árabe, que tem uma grande demanda no Rio de Janeiro e em outras cidades (ACNUR, 2019). Ao mesmo tempo, devido à dificuldade no processo de revalidação de diplomas e o difícil reconhecimento dos documentos por empregadores, outra parcela desses refugiados se veem obrigados a buscar empregos em outros setores diferentes daqueles de sua formação. Dessa forma, muitos não conseguem obter a remuneração equivalente ao que recebiam em seus países de origem, possibilitando outras vulnerabilidades sociais e econômicas pela falta de renda.

\section{A Sociedade Civil no Rio de Janeiro}

A partir da falta de ações práticas e diretas por parte das secretarias da Prefeitura da Cidade do Rio de Janeiro, as organizações da Sociedade Civil no município passam a ter um papel ainda mais ativo para tentar compensar tal abstenção. Existem diversas organizações que atuam com refugiados no Rio de Janeiro, contudo, grande parte é voltada para o processo de recepção e reconhecimento do status de refugiado de acordo com as normas brasileiras e poucas tem uma atuação ativa no processo após esse reconhecimento, ou seja, como esse refugiado vai ser integrado à sociedade carioca.

Uma dessas organizações é a PARES Caritas, criada na década de 1970, durante o Regime Militar, pela Arquidiocese do Rio de Janeiro e é uma das primeiras organizações da Sociedade Civil criada para o acolhimento e apoio de refugiados no Brasil (Andrade \& Marcolini, 2002). A Caritas do Rio de Janeiro hoje atua em diversos campos delimitados em três áreas: Proteção, Integração e Projetos. O campo de Proteção é responsável pelo acompanhamento do 
processo de reconhecimento dos direitos do refugiado, realizando entrevistas, elaborando pareceres e fornecendo as informações necessárias ao Comitê Nacional para os Refugiados (CARITAS, [s.d.]). Cabe destacar também que a organização possui um representante dentro do CONARE, que realiza tais decisões, o que expressa a relevância da organização no sistema de refúgio brasileiro (Andrade \& Marcolini, 2002).

O campo de Integração busca criar condições para que os refugiados (já reconhecidos como tal) se tornem parte da sociedade que os acolhe de forma autônoma, visando o acesso ao aprendizado do idioma, ao mercado de trabalho, à formação profissional, ao atendimento psicológico e subsídio financeiro para os casos mais necessários. Cabe destacar que a PARES Caritas é uma das poucas organizações na cidade do Rio de Janeiro que realiza esse tipo de atividade. Além disso, é importante reconhecer que a Caritas busca inserir o refugiado em diversos campos, não só o laboral e econômico, mas também o cultural, o social e o educacional (CARITAS, [s.d.]).

O setor de Projetos é mais amplo e oferece cursos de português; busca a integração dos refugiados nos ambientes educacionais da cidade ("Refugiados nas Escolas") e oferece aulas de Yoga voltadas para a melhoria da saúde física e psicológica dos refugiados. Além disso, cabe dar destaque a dois projetos da Organização: o Coletivo de Refugiados Empreendedores e os Grupos de Orientação (CARITAS, [s.d.]). O primeiro é um projeto de capacitação dos refugiados em empreendedorismo em parceria com o Serviço Brasileiro de Apoio às Micro e Pequenas Empresas do Rio de Janeiro (SEBRAE-RJ), qualificandoos em costura, gastronomia e formação de profissionais de cabelo. Um resultado dessas práticas pode ser observado nas feiras culturais que passaram a fazer parte do calendário cultural do Rio de Janeiro como a "Chega Junto", feira que reúne refugiados que residem no Rio de Janeiro e que têm a gastronomia como fonte de renda e reconexão com a cultura do seu país de origem. O segundo tem o objetivo de informar as pessoas em situação de refúgio sobre o cenário de trabalho no Brasil, explicando sobre o mercado de trabalho, os direitos trabalhistas e os processos seletivos de emprego, assim como discutir, em grupos separados, questões de gênero, saúde, relações familiares, emprego e violência.

É importante salientar que tais práticas da Caritas não devem ser as únicas formas de ação em relação aos refugiados, deixando tal responsabilidade apenas nas mãos da Sociedade Civil. A ausência do Executivo e do Legislativo 
da Cidade do Rio de Janeiro na formulação e aplicação de políticas públicas limita o acesso dos refugiados a serviços como cursos de português, ofertas de vagas de emprego e ações de fomento ao empreendedorismo e a promoção de suas culturas. Nesse contexto, a importância da Prefeitura nessa área se torna ainda maior, dado que outros atores (governos estadual e federal e a sociedade civil) não oferecem suficientemente tais serviços.

\section{Considerações finais}

De Haas (2012), Kuhlman (1991) e Chambers (1986) mostram que a atuação dos governos locais no processo de desenvolvimento e integração dos refugiados é fundamental para que possam ter uma qualidade de vida suficiente para sua permanência no local que o acolheu e, ao mesmo tempo, promovendo o desenvolvimento na cidade que o acolhe. Embora existam iniciativas para o seu desenvolvimento socioeconômico, a estrutura da Prefeitura da Cidade do Rio de Janeiro voltada para a integração laboral é bastante deficitária, o que acaba deixando a população refugiada residente na cidade sem acesso a diversos direitos e oportunidades. Nesse ambiente, o papel da Sociedade Civil como ator suplementar tornou-se ainda mais importante, sendo uma das organizações mais ativas na cidade a PARES Caritas, mesmo tendo suas limitações financeiras e logísticas. No entanto, a existência da Caritas não isenta a responsabilidade da Prefeitura em desenvolver políticas públicas voltadas para os refugiados.

Para que a Prefeitura se torne mais ativa no processo de integração laboral dos refugiados, permitindo que esses se desenvolvam da melhor forma, é importante pensar em políticas inspiradas em boas práticas feitas em outras cidades que precisaram lidar com esta questão. Neste sentido, as propostas apresentadas inspiram-se nas políticas públicas praticadas na Cidade de São Paulo, sob a Secretaria de Direitos Humanos e Cidadania, a partir de 2013. Desde então, a cidade é considerada referência em políticas públicas para a integração laboral e desenvolvimento socioeconômico de refugiados no Brasil.

Em primeiro lugar, sugiro que o Executivo e o Legislativo municipal desenvolvam ações voltadas ao ensino da língua portuguesa para os refugiados que não possuem conhecimento suficiente do idioma. Uma das possíveis ações nesse sentido é promover uma parceria com a PARES Caritas, fornecendo salas de aula no Rio de Janeiro e um programa de bolsas-auxílio para garantir que os 
refugiados possam passar o período de aprendizado com uma renda suficiente para sua manutenção e sobrevivência na cidade.

Em segundo lugar, sugiro o desenvolvimento de uma feira de empregos voltada para a população refugiada. Nessa feira, em parceria com a Caritas, o Governo do Estado e o Ministério do Trabalho, seriam oferecidas a emissão de documentos, como CPF e Carteiras de Trabalho, cadastro nas agências de emprego, em especial o Sistema Nacional de Emprego (SINE), orientação sobre direitos trabalhistas e previdenciários através de cartilhas e manuais, assim como encontros de contratação, em parceria com a iniciativa privada, buscando que o refugiado saia da feira já empregado. Dessa forma, a atuação da Prefeitura, do Estado e do Governo Federal são otimizados, e o refugiado é capaz de ter um meio de sobrevivência e desenvolvimento socioeconômico.

Em terceiro lugar, sugiro a criação de um fundo de incentivo ao empreendedorismo aos refugiados, buscando oferecer linhas de crédito e financiamentos a juros baixos, em parceria com os bancos públicos e privados para que aqueles refugiados que tenham interesse em empreender, independente do setor, possuam um fiador para desenvolver seu negócio no Rio de Janeiro. Em consonância à essa questão, sugiro também, junto ao Estado do Rio de Janeiro, um apoio presente na promoção e realização de eventos voltados ao potencial cultural dos refugiados, através da gastronomia, artesanato, dança e música, como a feira "Chega Junto", que acontece no bairro de Botafogo.

Em quarto, considero importante a realização de ações de combate ao preconceito e à xenofobia no Rio de Janeiro, incluindo os ambientes de trabalho. Sugiro, nesse sentido, a distribuição de folhetos e manuais aos centros de empregos e sindicatos que representam os refugiados, assim como a promoção de propagandas públicas a serem compartilhadas com a sociedade por meio da imprensa. Além desses elementos, ações junto ao Poder Judiciário para o enfrentamento e a punição dos casos de preconceito e xenofobia são fundamentais.

É importante reconhecer que ainda há muito a ser analisado sobre essa questão. Em primeiro lugar, é necessário o desenvolvimento de estudos estatísticos que informem com clareza quantos refugiados a cidade do Rio de Janeiro abriga, a desagregação de dados como gênero, raça e faixa etária e quais são suas principais necessidades durante o processo de integração na cidade. Dessa forma, a formulação de políticas públicas voltadas à integração 
laboral desses indivíduos pode ser melhor desenvolvida. Além disso, é necessária uma análise mais profunda sobre as competências das Secretarias Municipais, especialmente a Secretaria Municipal de Assistência Social e Direitos Humanos (SMASDH) e a Secretaria Municipal de Desenvolvimento, Emprego e Inovação (SMDEI), buscando encontrar possíveis estratégias de ação à integração laboral dos refugiados. Dessa maneira, será possível encontrar formas mais eficazes da cidade do Rio de Janeiro possuir um papel ativo, oferecendo condições de permanência e melhoria na qualidade de vida dos refugiados dentro do país.

\section{Referências bibliográficas}

ACNUR. Convenção Relativa ao Estatuto dos Refugiados. Nova York: 1951

_. Declaração de Cartagena. Cartagena das Índias: 1984.

- Perfil Socioeconômico dos Refugiados no Brasil: Subsídios para elaboração de políticas. Brasília: ACNUR, 2019

ALERJ. Lei n. 826/2015. Rio de Janeiro: Prefeitura da Cidade do Rio de Janeiro, Diário Oficial, 2015

ANDRADE, José H. F de; MARCOLINI, Adriana. A política brasileira de proteção e de reassentamento de refugiados - breves comentários sobre suas principais 16 características. Revista Brasileira de Política Internacional, v. 45, n.1, 2002, p. $168-176$.

BRASIL. Constituição Federal. Brasília: Governo Federal, 1988.

CARITAS. Números do Refúgio no Rio de Janeiro. Publicado em 18/10/2017. Disponível em: https://www.facebook.com/caritasrj/photos/a.160205424162181/8112770523883 45/?type=3\&theater. Acesso em: jun. 2019

CARITAS. Integração. [s.d.]. Disponível em: <http://www.caritasrj.org.br/integracao.html>. Acesso em: out. 2018

O Que Fazemos. [s.d.]. Disponível em: <http://www.caritas-rj.org.br/o-quefazemos.html.>. Acesso em: set. 2018 
_.Proteção. [s.d.]. Disponível em: <http://www.caritas-rj.org.br/protecao.html>. Acesso em: out. 2018

CHAMBERS, Robert. Hidden Losers? The Impact of Rural Refugees and Refugee Programs on Poorer Hosts. The International Migration Review, v. 20 n. 2, 1986, p.245-263.

CONARE. Refúgio em Números - 3ª̣ Edição. Brasília: 2018.

COURY, Paula; MILESI, Rosita; ROVERY, Julia. Migração Venezuelana ao Brasil: discurso político e xenofobia no contexto atual. Aedos, v. 10, n. 22, 2018, p. 53-70.

DE HAAS, Hein. The Migration and Development Pendulum: A Critical View on Research and Policy. International Migration, v. 50 n. 3, 2012.

INDA, João Paulo Baridó. A Inserção dos Refugiados no Mercado de Trabalho. 62p. Trabalho de Conclusão de Curso (Bacharel em Direito) -Rio de Janeiro: Universidade Federal do Estado do Rio de Janeiro, 2017.

KUHLMAN, Tom. The Economic Integration of Refugees in Developing Countries: A Research Model. Journal of Refugee Studies, v. 4, n.1, 1991.

LAUBENTHAL, Barbara. Refugees Welcome? Reforms of German Asylum Policies Between 2013 and 2017 and Germany's Transformation into an Immigration Country. German Politics, v. 28, n.3, 2019.

LIMA, João et al. Refúgio no Brasil: caracterização dos perfis sociodemográficos dos refugiados (1998-2014). Brasília: IPEA, 2017.

PREFEITURA DO RIO DE JANEIRO. 1 Plano Municipal de Direitos Humanos - Por um Rio de Direitos. Rio de Janeiro: Governo Municipal, 2014

Plano Municipal de Assistência Social (2018-2021). Rio de Janeiro: Governo Municipal, 2018. 